\title{
EDUCAÇÃO A DISTÂNCIA E A NEUROCIÊNCIA: OS FATORES QUE ENCANTAM OS ALUNOS
}

\author{
Márcia Gorett Ribeiro Grossi ${ }^{1}$ \\ Fabiane Angélica Aguiar² \\ Alanna Cristina Landim Souza ${ }^{3}$ \\ Shirley Doweslei Bernardes Borja ${ }^{4}$
}

\begin{abstract}
RESUMO: O objetivo desta pesquisa foi analisar a influência da empatia na relação professor - aluno na Educação a distância. Assim, foi realizada uma pesquisa científica qualitativa, descritiva e exploratória. Em relação aos procedimentos técnicos, escolheu-se o estudo de caso nos cursos técnicos ofertados a distância pelo CEFET-MG e os sujeitos do estudo foram os alunos. Os instrumentos de coleta escolhidos foram: observação online no Ambiente Virtual de Aprendizagem e questionário. Os resultados mostraram que a empatia e a emoção precisam estar presentes nas práticas pedagógicas realizadas via Moodle, sendo que para cada critério da neurociência existem estratégias específicas que, quando utilizadas com determinadas ferramentas digitais do Moodle, serão capazes de proporcionar a empatia entre professor e aluno. Verificou-se que os professores dos cursos estudados têm praticado a comunicação dialógica afetiva e conseguido estabelecer uma relação empática com seus alunos, o que os tem encantado, mantendo-os mais motivados a continuar no curso.
\end{abstract}

Palavras-chave: Neurociência. Educação a distância. Empatia.

1Doutora em Ciências da Informação. Professora titular do Centro Federal de Educação Tecnológica de Minas Gerais (CEFETMG) Belo Horizonte, MG/Brasil. E-mail: marciagrossi@terra.com.br

${ }^{2}$ Mestre em Educação Tecnológica. Professora de Idiomas na Rizvi International Schools (RIZVI) Belo Horizonte, MG/Brasil. Email: biany2005@gmail.com

${ }_{3}^{3}$ Mestranda em Educação Tecnológica de Minas Gerais (CEFET-MG) Belo Horizonte, MG/Brasil. E-mail: alannac.landim@gmail.com

${ }^{4}$ Mestre em Educação Tecnológica. Professora Faculdade Anhanguera de Belo Horizonte/MG Brasil. E-mail: shirley@bhsol.com.br 


\title{
DISTANCE EDUCATION AND THE NEUROSCIENCE: THE FACTORS THAT FASCINATE STUDENTS
}

\begin{abstract}
The aim of this research was to analyze the influence of empathy on the teacher - student relationship in Distance Education. Thus, qualitative, descriptive and exploratory scientific research was carried out. Regarding the technical procedures, the case study was chosen in the technical courses offered at distance by CEFET-MG and the subjects of the study was the students. The chosen instruments of collection were online observation in the Virtual Learning Environment and questionnaire. The results showed that empathy and emotion need to be present in the pedagogical practices carried out via Moodle, and for each criterion of neuroscience there are specific strategies that, when used with certain digital tools of Moodle, will be able to provide empathy between teacher and student. It was verified that the teachers of the studied courses have practiced the dialogical affective communication and managed to establish an empathic relationship with their students, which has charmed them, keeping them more motivated to continue in the course.
\end{abstract}

Keywords: Neuroscience. Distance education. Empathy.

\section{EDUCACIÓN A DISTANCIA Y NEUROCIENCIA: LOS FACTORES QUE ENCANTAN LOS ALUMNOS}

RESUMEN: El objetivo de esta investigación fue analizar la influencia de la empatía en la relación profesor - alumno en la Educación a distancia. Así, se realizó una investigación científica cualitativa, descriptiva y exploratoria. Con relación a los procedimientos técnicos, se escogió el estudio de caso en los cursos técnicos ofrecidos a distancia por el CEFET-MG y los sujetos del estudio fueron los alumnos. Los instrumentos de recolección elegidos fueron: observación online en el Ambiente Virtual de Aprendizaje y cuestionario. Los resultados mostraron que la empatía y la emoción necesitan estar presentes en las prácticas pedagógicas realizadas vía Moodle, siendo que para cada criterio de la neurociencia existen estrategias específicas que cuando se utilizan con determinadas herramientas digitales de Moodle, son capaces de proporcionar la empatía entre profesor y alumno. Se verificó que los profesores de los cursos estudiados han practicado la comunicación dialógica afectiva y logrado establecer una relación empática con sus alumnos, lo que les ha encantado, manteniéndolos más motivados para continuar en el curso.

Palabras clave: Neurociencia. Educación a distancia. Empatia. 
Atualmente a abrangência da Educação a distância (EaD) alcança diversos níveis acadêmicos, da formação profissionalizante à pós-graduação, com o respaldo do Ministério da Educação (MEC) que regulamentou esta modalidade de ensino em todo território nacional. A modalidade a distância cresce a cada ano, como pode ser verificado nos dados apresentados no Censo EaD.BR 2016, coletados pela equipe da Associação Brasileira de Educação a Distância (ABED): no ano de 2016 o número de matrículas foi de 55.860 nos 219 cursos ofertados totalmente a distância e apresentou crescimento de $27 \%$ em comparação a 2015 , ano em que houve 43.841 matrículas nos 184 cursos técnicos ofertados totalmente a distância.

Ainda de acordo com o Censo, todos os níveis acadêmicos e todas as áreas do conhecimento contam com ofertas de vagas em cursos a distância no país, como por exemplo, os cursos técnicos que cresceram significativamente nos últimos anos, apresentando $213 \%$ de aumento no número de vagas entre 2006 e 2016. Diante de tal fato, pode-se verificar que a “[...] presença massiva de cursos técnicos e profissionalizantes e, mesmo das licenciaturas, reforçam o valor da EaD para atender as demandas práticas de educação com resultados rápidos e perceptíveis na empregabilidade" (ABED, 2016, p. 40).

Porém, os desafios encontrados pela EaD são muitos, dentre os quais, a evasão escolar, como pode ser observado no relatório do censo EaD.BR 2016: a taxa de evasão dos cursos totalmente a distância está na faixa entre $11 \%$ e $25 \%$, e os semipresenciais entre $6 \%$ e $10 \%$. No caso dos cursos técnicos ofertados a distância no Centro Federal de Educação Tecnológica de Minas Gerais (CEFET-MG), locus deste estudo, há números preocupantes: a Turma 2010 teve evasão de 73,6\%, a Turma de 2011 evasão de 74\%, a Turma de 2012, 89\% e a Turma 2014, 95,5\% (OLIVEIRA, 2017). O mesmo autor afirma que o principal motivo alegado pelos alunos evadidos foi a falta de adaptação à metodologia dos cursos e, por isto eles alegaram ficar desmotivados.

Assim, recorre-se a Bzuneck (2009) para compreender o que é a motivação. Para o autor, é aquilo que move uma pessoa, que a põe em ação ou a faz mudar de curso. Ribeiro (2011) alerta que a falta de motivação é o primeiro obstáculo à compreensão e aprendizagem dos conteúdos escolares. Nas palavras de Gagné (1985), a motivação é uma pré-condição para a aprendizagem e, quando o aluno perde o interesse nos cursos, principalmente naqueles a 
distância, ele não aprende e abandona o curso. Tão importante quanto a motivação, são a empatia e a emoção nos ambientes escolares, pois elas compõem também as bases do aprendizado.

Então, para tentar compreender as causas da evasão nos cursos a distância, uma das possibilidades é "conhecer o funcionamento, potencialidades e limitações do sistema nervoso, visto que tal conhecimento possibilita atender às demandas do educador frente às dificuldades de aprendizagem, levando a uma contribuição positiva na prática pedagógica" (GROSSI et al., 2014), e aplicar os conhecimentos da neurociência nas práticas pedagógicas dos cursos ofertados a distância. Isso remete ao que Martins et al. (2017, p. 180) explicam: "aprendemos sobretudo com as emoções que sentimos na consequência de uma experiência", aprendemos o que nos emociona positivamente, o que desperta a curiosidade. Para os autores, "as emoções positivas, como a alegria, ativam uma área do cérebro chamada nucleus accumbens, considerada um dos principais centros de prazer do cérebro, sem as quais não teríamos motivação para viver, estudar ou trabalhar" (p.182).

Além disso, outra habilidade chave na aprendizagem é a empatia, que consiste na capacidade de tentar sentir o que outra pessoa sente, ouvindo e compreendendo seus problemas e emoções. Dessa forma é que as relações sociais são estabelecidas. Essa ideia fica evidenciada em Tassinari e Durange (2014, p. 54) ao afirmarem que "uma das funções importantes da empatia é legitimar a humanidade: ao ser profundamente compreendido por outro ser humano, sinto-me mais pertencente à espécie humana".

Assim, levar a habilidade da empatia para a sala de aula convencional, ou do ensino presencial, não é uma tarefa muito complicada, pois o professor está fisicamente junto aos seus alunos. Ele pode ver as expressões nos rostos dos seus alunos, pode ouvir seus problemas, sentir suas dificuldades e perceber se o caminho pedagógico escolhido está dando certo, podendo fazer alterações para melhorar os processos de ensino e aprendizagem. Porém, o que acontece quando o ensino não é mais presencial? Como estabelecer a relação empática entre quem está distante fisicamente e/ou temporalmente?

Para responder essas perguntas, o objetivo deste artigo foi analisar a influência da empatia na relação professor - aluno na EaD. Para isso, foi realizado, em 2018, um estudo de 
caso no Centro Federal de Educação Tecnológica de Minas Gerais (CEFET-MG), especificamente nos cursos técnicos ofertados na modalidade a distância.

Do ponto de vista da relevância acadêmica que justificasse esta pesquisa, decidiu-se realizar uma consulta na base de dados disponíveis na Biblioteca Digital Brasileira de Teses e Dissertações (BDTD), mantida pelo Instituto Brasileiro de Informação em Ciência e Tecnologia (IBICT), para levantar o que tem sido produzido sobre o tema educação e empatia. A consulta foi realizada em julho de 2018. A seleção para a escolha dos trabalhos produzidos (teses e dissertações) guiou-se pelos seguintes passos:

1) Seleção das pesquisas publicadas na biblioteca BDTD do IBICT utilizando os descritores: Educação e Empatia; Processo de Aprendizagem; e Empatia e Sala de aula e Empatia.

2) Foram encontrados 109 trabalhos, em um recorte temporal de 2012 até o ano de 2017.

3) Seleção dos trabalhos que se referiam efetivamente ao tema pesquisado a partir da leitura do título, das palavras chave, do resumo e, em alguns casos do trabalho completo. Dos 109 trabalhos encontrados no 10 passo, 66 se referiam efetivamente ao tema pesquisado, o que para um período de cinco anos, é um número tímido. Esse resultado demonstra a necessidade de pesquisas acerca da temática, o que demonstra a relevância deste artigo.

\section{Educação a distância: Algumas considerações}

De acordo com informações divulgadas pelo Instituto Brasileiro de Geografia e Estatística (IBGE), em 2016, 69,3\% dos domicílios particulares permanentes do país faziam uso da internet. Além de uma maior facilidade de acesso, outros fatores relacionados à legislação têm contribuído para o crescimento da EaD no Brasil, tais como a portaria no 1.134 , de 10 de outubro de 2016, que regulamenta que instituições de ensino superior possam ofertar até 20\% da carga horária total de disciplinas na modalidade a distância e, a chamada reforma do ensino médio, Lei no 13.415, de 16 de fevereiro de 2017, com a alteração no artigo 36 da Lei no 9.394, de 20 de dezembro de 1996, parágrafo 11, o qual afirma ser agora possível reconhecer competências e firmar convênios com instituições de educação a distância com 
notório reconhecimento. Além disso, o Artigo 33 da Resolução no 6, de 20 de setembro de 2012, regulamenta que até $80 \%$ da carga horária total de cursos de nível técnico podem ser ofertados à distância.

A EaD é uma modalidade de ensino que passou por vários processos de mudanças que, como Moore e Kearsley (2013) explicam, se resume a cinco gerações: 1a) correspondência;

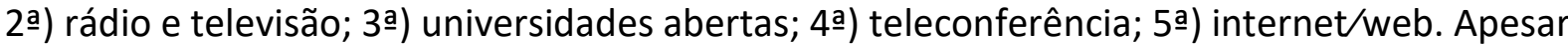
das distinções entre tais gerações, devido às principais tecnologias de informação e comunicação utilizadas (TIC), o que há em comum entre elas é o fato de que a educação a distância pressupõe que alunos e professores interajam de locais diferentes, em momentos distintos, por meio da tecnologia. Essa distância espaço-temporal é uma característica típica da EaD.

Moore (1993) trata de uma distância transacional, referente à separação psicológica e comunicacional entre alunos e professores, em virtude da distância espaço-temporal. A teoria da distância transacional, como é conhecida, "estabelece uma relação entre a estrutura dos programas educacionais, a interação entre alunos e professores e a natureza e o grau de autonomia do aluno" (VALENTE; MORAN; ARANTES, 2011, n.p.5). Carmo (2016) esclarece que “diálogo e estrutura são considerados variáveis de ensino" e "a autonomia é definida como uma variável da aprendizagem" (CARMO, 2016, online).

Com base nessa teoria, a distância psicológica e comunicacional, ou transacional, entre alunos e professores na EaD, é inversamente proporcional às oportunidades de diálogo, flexibilidade da estrutura do curso e autonomia do aluno (VALENTE; MORAN; ARANTES, 2011). Então, visto que as distâncias espaciais e temporais são uma condição sine qua non para a modalidade a distância, a distância transacional pode ser um fator preponderante na EaD. Logo, promover um ambiente onde o aluno tenha liberdade para exercer sua autonomia, onde haja oportunidades de estabelecer uma comunicação dialógica e, flexibilidade na estrutura do curso são condições imprescindíveis para aproximar alunos e professores.

\footnotetext{
${ }^{5}$ Fonte: Leitor de livros digitais (Kindle)
} 


\section{Neurociência: $O$ que já conhecemos sobre esta área}

Há vários aspectos envolvidos no processo de aprendizagem: sociais, psicológicos, e neurobiológicos, dentre outros. Novaes (2010) salienta que, por ultrapassarem a esfera individual, no ambiente escolar tais aspectos precisam ser relacionados com os campos de interação com o indivíduo, levando em consideração as relações sociais envolvidas. Carter et al. (2012) destacam que "o ser humano é uma espécie intensamente social", por isto, há no cérebro "circuitos cerebrais distintos para o apego, para a cooperação e para prever as ações dos outros", ao que as autoras denominam de "cérebro social" (CARTER et al., 2012, p. 136).

Uma das várias características desse cérebro social é a capacidade de sentir empatia, que é definida por Carter et al. (2012, p. 138) como um "eco das emoções alheias" e por Vignemont e Singer (2006) como a habilidade de compartilhar o estado emocional do outro. Nesse caminho, a empatia é assim concebida por Kandel et al. (2014):

Sentimentos complexos estão associados à interação social [...]. Assim como no caso de emoções primárias, como o medo, o prazer ou a tristeza, emoções sociais consistem em alterações corporais e comportamentos específicos e são experimentados conscientemente, como sentimentos distintos. Esses sentimentos contribuem de forma importante para interações sociais normais (KANDEL et al., 2014, p. 946).

Dando continuidade ao que já se conhece sobre o cérebro, pode-se afirmar que ele possui regiões e estruturas específicas para tal capacidade, dentre elas, um grupo distinto de células chamadas neurônios-espelho. Esse grupo de neurônios, descoberto na década de 1990 acidentalmente por um grupo de pesquisadores italianos, é ativado quando se observa outra pessoa fazendo um movimento e quando outra pessoa se emociona. Esses fenômenos são denominados espelhamento do movimento e espelhamento das emoções, respectivamente e, "acredita-se que o espelhamento das emoções seja a base da empatia" (CARTER et al., 2012, p. 121).

Sabendo que a empatia é compreender as emoções do outro como se fossem suas próprias (COSENZA; GUERRA, 2014), e ao pensar a questão da distância espaço-temporal na educação a distância, percebe-se como é salutar buscar diminuir a distância transacional, a fim de praticar a empatia. Considerando que "o melhor professor a distância tem empatia e 
capacidade para entender as personalidades de seus alunos, mesmo quando filtradas pelas comunicações transmitidas tecnologicamente" (MOORE; KEARSLEY, 2013, p. 179), e que o tutor deve se valer de habilidades como a empatia (FARIA, 2010), é primordial estabelecer uma comunicação dialógica empática no ambiente virtual.

Nesse sentido, Hack (2010, p. 16) afirma que o processo comunicacional dialógico é de suma importância "na construção do conhecimento na modalidade a distância", e que "o tutor precisa estabelecer uma interlocução constante com o aprendiz através de TIC que permitam uma comunicação de mão dupla entre as partes". A partir dessas necessidades, o autor identificou cinco bases para uma comunicação dialógica afetiva:

1a) Habilidade de conviver com as diferenças, criando um ambiente onde o aluno se sinta pertencente e à vontade para se expor, respeitando e sendo respeitado.

2ª) Assiduidade na comunicação não-presencial, com feedbacks constantes.

3a) Proximidade e identidade entre as partes envolvidas, com conversas informais e o diálogo aberto entre pares.

4a) Descontração eventual, com momentos recreativos e práticas que ampliem a comunicação interpessoal.

5a) Maturidade e responsabilidade individual para o desenvolvimento da autonomia e consciência quanto aos direitos e deveres de cada indivíduo (HACK, 2010, p. 16-17).

Partindo dessas cinco bases para uma comunicação dialógica afetiva e do que fora discutido até o momento acerca da empatia e sua relação com a aprendizagem na educação a distância, faz-se necessário repensar as estratégias pedagógicas e as atitudes docentes. Assim, partindo das ideias de Hack (2010) sobre a base da comunicação dialógica afetiva, as autoras deste artigo elencaram sete atitudes que os professores devem ter para estabelecerem uma relação de empatia com seus alunos:

1a) Ter flexibilidade, como por exemplo, quanto ao prazo de entrega de atividades e da participação dos alunos nas escolhas das estratégias pedagógicas.

2ª) Usar ferramentas e estratégias pedagógicas variadas, a fim de incluir nas atividades alunos com diferentes perfis e habilidades.

3a) Oferecer oportunidades de interação para que os alunos possam ser participantes 
ativos no processo de aprendizagem.

4a) Dar feedback apropriado e com gentileza, tanto positivo como negativo.

5a) Possuir uma comunicação e postura adequadas, com respeito, assertividade e pontualidade.

6a) Demonstrar confiança na aprendizagem dos alunos.

7ạ) Encorajar e motivar os alunos a estudarem, mostrando os aspectos positivos da educação.

Aliado a essa visão, Migliori (2013, p. 77) defende que "a vontade de aprender é característica essencial do ser humano, mas necessita de estímulos externos e internos, motivação e necessidades"; por isto, os professores devem ser conscientes da importância da comunicação dialógica afetiva entre eles e seus alunos, estimulando-os externamente a aprender. Em especial, no caso de alunos adolescentes, essa comunicação é ainda mais necessária, visto que o cérebro adolescente continua em fase de maturação da região préfrontal, responsável, dentre outras coisas, pelas funções executivas, que são fundamentais nas atividades educacionais (COSENZA; GUERRA, 2014).

\section{Um diálogo entre a EaD e a Neurociência}

Dentre as abordagens que estudam a neurociência, este artigo focou na neurociência cognitiva, que investiga as capacidades mentais mais complexas como a aprendizagem, linguagem, memória, planejamento (GROSSI et al., 2014). Portanto, do que se viu até aqui, pode-se afirmar que "o cérebro é o órgão do conhecimento" (COSENZA; GUERRA, 2014, p. 142), por isto a importância do diálogo entre a educação e a neurociência, trazendo para a sala de aula conhecimentos sobre como o cérebro recebe as informações, as processa, as guarda em forma de memórias e, enfim, como aprende.

Dessa forma Lourenço e De Paiva (2010) lançaram alguns questionamentos, tais como: como proporcionar esse diálogo quando a sala de aula não é mais física e os professores e alunos não estão juntos geograficamente e, em algumas vezes nem temporalmente, como na EaD? Como a neurociência pode contribuir? Como motivar um aluno a distância, uma vez que motivá-los é um desafio fundamental nos processos de ensino e aprendizagem, pois tem 
implicações diretas na qualidade do envolvimento do aluno neste processo? Preocupadas com essas questões, Grossi e Borja (2016) desenvolveram oito critérios que devem ser observados nos cursos oferecidos na modalidade a distância, para verificar se os conhecimentos sobre a neurociência estão presentes nas aulas disponíveis em seus Ambientes Virtuais de Aprendizagem (AVA):

1ํ) Promover horários de aula diferenciados (flexíveis).

2ㅇ) Utilizar diferentes ferramentas digitais presentes nos AVA.

3) Oportunizar aprendizagem personalizada, considerando os estilos individuais de aprendizagem.

4으) Desenvolver materiais didáticos variados.

50) Proporcionar diferentes estratégias pedagógicas.

60) Estimular atividades que promovam a interação entre alunos-professores; alunosalunos e alunos-tutores.

70) Motivar os alunos durante o processo de ensino e aprendizagem.

8ㅇ) Criar situações para provocar a curiosidade no aluno, estimulando a construção do conhecimento.

De acordo com as autoras, esses princípios também são válidos para as aulas de cursos presenciais. Além disso, Grossi e Borja (2015) afirmam que é possível aplicar os conhecimentos da neurociência, devido ao avanço das tecnologias utilizadas nos AVA.

\section{Os cursos técnicos ofertados a distância pelo CEFET-MG: principais} informações

Com o intuito de democratizar o acesso aos cursos técnicos a distância no Brasil, o MEC, por meio do Decreto $\mathrm{n}^{\circ} 6.301$ de 12 de dezembro de 2007, criou o Sistema Escola Técnica Aberta do Brasil - e-Tec Brasil, o qual foi revogado em 2011 e substituído pelo Decreto no 7.589, de 26 de outubro de 2011, que criou a Rede e-Tec Brasil (BRASIL, 2011). Para a viabilização dos cursos, foram feitas parcerias entre o MEC e instituições de ensino, como por exemplo, com o CEFET-MG, que se credenciou junto ao MEC, tornando-se habilitado a 
implantar a EaD nos cursos técnicos de nível médio em Planejamento e Gestão em Tecnologia da Informação (PGTI), o qual teve seu nome mudado para Informática para Internet, Meio Ambiente e Eletroeletrônica e, começou a ser ofertado a distância em 2010.

Nesse mesmo ano foi criado o Núcleo de Educação a Distância (NEaD) do CEFET-MG com o objetivo de montar uma equipe para gerenciar seus cursos, coordenando, acompanhando e administrando toda a sua logística. O NEaD, que fica localizado em Belo Horizonte, no Campus II do CEFET-MG, conta com profissionais das áreas pedagógica e tecnológica responsáveis pela coordenação geral dos cursos, e coordenadores de curso, professores e tutores a distância. Além disso, existem os pólos presenciais para apoio aos alunos nas seguintes cidades mineiras: Belo Horizonte, Campo Belo, Contagem, Curvelo, Divinópolis, Leopoldina, Nepomuceno, Nova Lima, Timóteo, Varginha. Em 2017, a parceria com a Rede e-Tec foi finalizada. Porém, o CEFET-MG continuou ofertando os cursos com o apoio da direção geral da instituição. Assim, atualmente o curso possui 10 polos de apoio presencial, cuja situação dos alunos matriculados está apresentada na Tabela 1.

Tabela 1 - Total de alunos dos cursos técnicos a distância do CEFET-MG Turma 2018.

\begin{tabular}{lccc}
\hline Cursos & $\begin{array}{c}\text { Total de alunos } \\
\text { matriculados }\end{array}$ & $\begin{array}{c}\text { Total de alunos } \\
\text { evadidos }\end{array}$ & $\begin{array}{c}\text { Total de alunos } \\
\text { frequentes }\end{array}$ \\
\hline Eletroeletrônica & 334 & 54 & 280 \\
Informática & 198 & 53 & 145 \\
Meio Ambiente & 216 & 42 & 174 \\
$\quad$ Total & $\mathbf{7 4 8}$ & $\mathbf{1 4 9}$ & $\mathbf{5 9 9}$ \\
\hline
\end{tabular}

Fonte: Dados do NEaD do CEFET-MG (2018).

Sobre o AVA, o escolhido pela equipe do NEaD foi o Modular Object-Oriented Dynamic Learning Environment (Moodle). Essa escolha foi devido aos seguintes motivos: ser um software livre, que possui código de programação aberto e é de acesso gratuito; possuir uma diversidade de ferramentas digitais, além das suas características, tais como, usabilidade, confiabilidade e mobilidade. 


\section{Moodle: O Ambiente Virtual de Aprendizagem em foco}

De acordo com Grossi et al. (2018, p. 516), o Moodle é um "ambiente virtual de gestão de aprendizagem online gratuito que permite que os educadores criem seu próprio portal privado com seus cursos ofertados a distância que possam ser feitos a qualquer hora e em qualquer lugar". Portanto, caracteriza-se como Open Source ou Software Livre, por ser fornecido gratuitamente, podendo ser adaptado, estendido ou modificado de acordo com a necessidade do projeto da instituição que irá utilizá-lo.

Esse Ambiente Virtual de Aprendizagem (AVA) é composto por diversas ferramentas digitais que propiciam a interação dos participantes durante o curso ou disciplina. Essas ferramentas permitem discussões, resolução de exercícios, troca de mensagens entre outros. Porém, cabe aos professores identificarem as ferramentas mais adequadas, de acordo com seus objetivos e até mesmo perfil dos participantes. Como lembra Prado (s.d., p. 4), "geralmente, estas ferramentas, do ponto de vista técnico, são simples de serem manipuladas, mas as possibilidades e implicações pedagógicas dependem da (re)significação que o professor pode fazer no contexto do curso". O Quadro 1 apresenta as ferramentas digitais do Moodle e as suas possíveis aplicações, baseado em dados do site oficial do Moodle ${ }^{6}$, bem como de observação online do Moodle do CEFET-MG.

\footnotetext{
${ }^{1}$ Disponível em: https://docs.moodle.org. Acesso em: 14 jul. 2018.
} 
Quadro 1 - Ferramentas digitais presentes no Moodle.

\begin{tabular}{|l|l|}
\hline Ferramentas Digitais & \multicolumn{1}{c|}{ Funções } \\
\hline Fórum & $\begin{array}{l}\text { Permitir a alunos e professores a troca de ideias com base em comentários, } \\
\text { classificados em tópicos. }\end{array}$ \\
\hline Tarefa & $\begin{array}{l}\text { Fornecer um espaço no qual os alunos podem enviar trabalhos para os } \\
\text { professores avaliarem e darem feedback. }\end{array}$ \\
\hline Chat & $\begin{array}{l}\text { Permitir uma conversa em tempo real entre os alunos do curso e os } \\
\text { formadores. }\end{array}$ \\
\hline Escolha & $\begin{array}{l}\text { Permitir que se faça uma pergunta e configure os botões de opção nos quais } \\
\text { os alunos podem clicar para fazer uma seleção de várias respostas possíveis. }\end{array}$ \\
\hline Base de Dados & $\begin{array}{l}\text { Permitir que o professor e/ou os alunos criem, exibam e pesquisem um } \\
\text { banco de entradas de registros sobre qualquer tópico concebível. }\end{array}$ \\
\hline URL & $\begin{array}{l}\text { Permitir que os participantes interajam com os recursos e atividades de } \\
\text { aprendizado compatíveis com o padrão IMS para Interoperabilidade da } \\
\text { Ferramenta de Aprendizagem em outros sites. }\end{array}$ \\
\hline Comentários & Permitir a criação e condução de pesquisas para coletar feedback. \\
\hline Glossário & $\begin{array}{l}\text { Permitir que os participantes criem e mantenham uma lista de definições, } \\
\text { como um dicionário. }\end{array}$ \\
\hline Lição & $\begin{array}{l}\text { Permitir ao aluno fazer algum tipo de escolha abaixo da área de conteúdo. } \\
\text { A escolha irá enviá-los para uma página específica na lição. }\end{array}$ \\
\hline Quis & $\begin{array}{l}\text { Permitir que o professor construa questionários consistindo em uma grande } \\
\text { variedade de tipos de perguntas, incluindo múltipla escolha, verdadeiro- } \\
\text { falso, resposta curta e arrastar e soltar imagens e texto. Essas perguntas são } \\
\text { mantidas no banco de perguntas e podem ser reutilizadas em diferentes } \\
\text { questionários. }\end{array}$ \\
\hline Wesquisa & $\begin{array}{l}\text { Fornece uma série de instrumentos de pesquisa verificados, que foram úteis } \\
\text { para avaliar e estimular a aprendizagem online. Os professores podem usá- } \\
\text { los para coletar dados de seus alunos que os ajudarão a aprender sobre sua } \\
\text { classe e refletir sobre seu próprio ensino. }\end{array}$ \\
\hline Oficina & $\begin{array}{l}\text { Permitir a avaliação de pares. } \\
\text { wermitir a utilização e reutilização de objetos de aprendizagem baseado na } \\
\text { wCORM }\end{array}$ \\
\hline Permitir a criação de exercícios sob a forma de objetos digitais. \\
\hline Fontes
\end{tabular}

Fonte: Dados de pesquisa (2018).

\section{Metodologia}

\section{Caracterização da pesquisa}

Optou-se neste estudo pela pesquisa científica de natureza qualitativa. De acordo com o objetivo traçado, os tipos escolhidos de pesquisa foram a pesquisa descritiva e a exploratória. Em relação a procedimentos técnicos, escolheu-se o estudo de caso. $\mathrm{O}$ universo 
da pesquisa foram os cursos técnicos ofertados na modalidade a distância pelo CEFET-MG. Atualmente, a instituição oferece três cursos técnicos a distância: Eletroeletrônica, Meio Ambiente, Informática para Internet. Já os sujeitos do estudo foram compostos por todos os alunos desses três cursos, que totalizam 599 (Tabela 1).

\section{Técnicas para coleta de dados}

Para a realização do procedimento de levantamento de dados, os instrumentos de coleta escolhidos foram: observação online e questionário. A observação não foi participante, ou seja, as pesquisadoras não se envolveram e não se tornaram membros do grupo, podendo assim observar mais fidedignamente os fenômenos que ocorrem no Moodle. Quanto ao questionário, esse foi aplicado a todos os 599 alunos e, foi organizado em quatro partes: a 1a parte foi constituída por cinco questões referentes ao perfil dos alunos; a 2 a parte foi constituída por oito perguntas de múltipla escolha que tinham por finalidade verificar a percepção dos alunos sobre a aplicação dos critérios da neurociência nos seus cursos; a 3a parte também foi constituída por oito perguntas de múltipla escolha que tinham por finalidade verificar a percepção dos alunos quanto às atitudes empáticas de seus professores e, a última parte foi constituída por duas questões (uma de múltipla escolha e uma aberta), para verificar a questão da permanência do aluno no curso.

Antes da aplicação do questionário, foi feito um pedido de autorização ao coordenador geral dos cursos técnicos ofertados a distância do CEFET-MG para a realização da pesquisa junto aos alunos. Assim que houve o consentimento do coordenador geral, foi enviado um convite a todos os alunos por meio de mensagem pelo Moodle, bem como um e-mail para cada aluno, separadamente, informando sobre a pesquisa e solicitando a participação em um questionário. Nesse e-mail, foram fornecidas aos alunos as instruções para preenchimento do questionário e um link para acesso ao mesmo. Portanto, a partir desse link, o aluno tinha acesso ao questionário, que se encontrava no aplicativo Googledocs. Obteve-se 175 questionários respondidos, o que representou uma taxa de retorno de $29,2 \%$.

Para o desenvolvimento da pesquisa, esta foi dividida em cinco etapas:

1a etapa: Critérios da neurociência, as estratégias pedagógicas e as ferramentas digitais do Moodle para proporcionar a empatia. Para ela foram feitas observações online no 
Moodle do NEaD do CEFET-MG. Para que a observação fosse realizada foi solicitada a concessão de um usuário para o manuseio do Moodle, autorizado pela coordenação geral dos cursos.

2a etapa: Identificação dos respondentes.

3a etapa: Verificação da aplicação dos critérios da neurociência nos processos de ensino e aprendizagem.

4a etapa: Verificação das atitudes dos professores em relação à empatia.

5a etapa: Sobre a permanência no curso: com duas questões.

\section{Resultados e análises}

1a etapa: Critérios da neurociência, as estratégias pedagógicas e as ferramentas digitais do Moodle para proporcionar a empatia.

Como o foco deste artigo foi a empatia, foi elaborado um quadro em que estão apresentados a relação entre os critérios da neurociência para a EaD e os princípios da base da comunicação dialógica afetiva. Além disso, foram relacionadas as estratégias pedagógicas e as ferramentas digitais presentes no Moodle (Quadro 1) que podem ser utilizadas em cursos a distância, para ajudar os professores a terem atitudes empáticas com seus alunos (Quadro 2).

Quadro 2 - Critérios da neurociência, as estratégias pedagógicas e as ferramentas digitais do Moodle para proporcionar a empatia. 
M. G. R. GROSSI

F. A. AGUIAR

A. C. L. SOUZA

S. D. B. BORJA

\begin{tabular}{|c|c|c|c|}
\hline $\begin{array}{ll}\text { Critérios } & \text { da } \\
\text { Neurociência } & \end{array}$ & $\begin{array}{l}\text { Atitudes do professor que } \\
\text { levam à empatia }\end{array}$ & $\begin{array}{l}\text { Estratégias pedagógicas na } \\
\text { EaD }\end{array}$ & $\begin{array}{l}\text { Ferramentas } \\
\text { digitais presentes } \\
\text { no Moodle }\end{array}$ \\
\hline $\begin{array}{l}1 . \quad \text { Promover } \\
\text { horários de aula } \\
\text { diferenciados } \\
\text { (flexíveis). }\end{array}$ & $\begin{array}{l}\text { - Ter flexibilidade em relação às } \\
\text { datas das atividades. }\end{array}$ & - Interação via redes sociais & $\begin{array}{l}\text { - Fóruns } \\
\text { - Chats }\end{array}$ \\
\hline $\begin{array}{l}2 . \quad \text { Utilizar } \\
\text { diferentes } \\
\text { ferramentas } \\
\text { digitais presentes } \\
\text { nos AVA. }\end{array}$ & $\begin{array}{l}\text { - Usar ferramentas e estratégias } \\
\text { pedagógicas variadas, a fim de } \\
\text { incluir nas atividades alunos com } \\
\text { diferentes perfis e habilidades. }\end{array}$ & $\begin{array}{l}\text { - Uso de filmes/vídeos com } \\
\text { ou sem debates e } \\
\text { discussões } \\
\text {-Músicas } \\
\text { - Aulas dialogadas } \\
\text { - Videoconferência }\end{array}$ & $\begin{array}{l}\text { - Lição } \\
\text { - Tarefas } \\
\text { - Fóruns } \\
\text { - Chats } \\
\text { - Glossário }\end{array}$ \\
\hline $\begin{array}{l}3 . \quad \text { Oportunizar } \\
\text { aprendizagem } \\
\text { personalizada, } \\
\text { considerando os } \\
\text { estilos individuais } \\
\text { de aprendizagem. } \\
\end{array}$ & $\begin{array}{l}\text { - Usar ferramentas e estratégias } \\
\text { pedagógicas variadas, a fim de } \\
\text { incluir nas atividades alunos com } \\
\text { diferentes perfis e habilidades. }\end{array}$ & $\begin{array}{l}\text { - Solução de problemas } \\
\text { - Avaliações } \\
\text { - Brainstorming } \\
\text { - Estudo de caso }\end{array}$ & $\begin{array}{l}\text { - Lição } \\
\text { - Tarefas } \\
\text { - Fóruns } \\
\text { - Chats }\end{array}$ \\
\hline $\begin{array}{l}4 . \quad \text { Desenvolver } \\
\text { materiais didáticos } \\
\text { variados. }\end{array}$ & $\begin{array}{l}\text { - Usar ferramentas e estratégias } \\
\text { pedagógicas variadas, a fim de } \\
\text { incluir nas atividades alunos com } \\
\text { diferentes perfis e habilidades. }\end{array}$ & $\begin{array}{l}\text { - Portfólio } \\
\text { - Discussões e debates } \\
\text { - Simpósios } \\
\text { - Podcast } \\
\text { - Palestras } \\
\text { - Músicas }\end{array}$ & $\begin{array}{l}\text { - Fóruns } \\
\text { - Chats } \\
\text { - Wiki } \\
\text { - URL }\end{array}$ \\
\hline $\begin{array}{l}\text { 5. Proporcionar } \\
\text { diferentes } \\
\text { estratégias } \\
\text { pedagógicas. }\end{array}$ & $\begin{array}{l}\text { - Usar ferramentas e estratégias } \\
\text { pedagógicas variadas, a fim de } \\
\text { incluir nas atividades alunos com } \\
\text { diferentes perfis e habilidades. }\end{array}$ & $\begin{array}{l}\text { - Solução de problemas } \\
\text { - Avaliações } \\
\text { - Brainstorming } \\
\text { - Aula expositiva dialogada } \\
\text { - Lista de discussão } \\
\text { - Estudo de caso }\end{array}$ & $\begin{array}{l}\text { - Lição } \\
\text { - Tarefas } \\
\text { - Fóruns } \\
\text { - Chats } \\
\text { - Glossário }\end{array}$ \\
\hline $\begin{array}{lr}6 . & \text { Estimular } \\
\text { atividades } & \text { que } \\
\text { promovam a } & \text { a } \\
\text { interação entre } \\
\text { alunos-professores; } \\
\text { alunos-alunos } \quad \text { e } \\
\text { alunos-tutores. }\end{array}$ & $\begin{array}{l}\text { - Demonstrar confiança na } \\
\text { aprendizagem do seu aluno. } \\
\text { - Encorajar os seus alunos a } \\
\text { estudarem, mostrando os } \\
\text { aspectos positivos da educação. } \\
\text { - Utilizar uma comunicação } \\
\text { afetiva e respeitosa com os } \\
\text { alunos. } \\
\text { - Oferecer Feedback positivo. } \\
\text { - Criar oportunidades de } \\
\text { interação aluno-professor e } \\
\text { aluno-aluno. }\end{array}$ & $\begin{array}{l}\text { - Seminários } \\
\text { - Gincanas virtuais } \\
\text { - Competições culturais } \\
\text { virtuais } \\
\text { - Debates e júri simulado } \\
\text { - Grupo de verbalização e } \\
\text { de observação (GVGO) }\end{array}$ & $\begin{array}{l}\text { - Fóruns } \\
\text { - Chats } \\
\text { - Escolha } \\
\text { - Glossário }\end{array}$ \\
\hline $\begin{array}{l}\text { 7. Motivar os } \\
\text { alunos durante o } \\
\text { processo de ensino }\end{array}$ & $\begin{array}{l}\text { - Demonstrar confiança na } \\
\text { aprendizagem do seu aluno. } \\
\text { - Encorajar os seus alunos a }\end{array}$ & $\begin{array}{l}\text { - Aula expositiva dialogada } \\
\text { - Lista de discussão } \\
\text { - Videoconferência }\end{array}$ & $\begin{array}{l}\text { - Páginas } \\
\text { - URL } \\
\text { - Fóruns }\end{array}$ \\
\hline
\end{tabular}




\begin{tabular}{|c|c|c|c|}
\hline e aprendizagem. & $\begin{array}{l}\text { estudarem, mostrando os } \\
\text { aspectos positivos da educação. } \\
\text {-Utilizar uma comunicação } \\
\text { afetiva e respeitosa com os } \\
\text { alunos. } \\
\text { - Oferecer Feedback positivo. } \\
\text { - Criar oportunidades de } \\
\text { interação aluno-professor e } \\
\text { aluno-aluno. }\end{array}$ & & - Chats \\
\hline $\begin{array}{l}\text { 8. Criar situações } \\
\text { para provocar a } \\
\text { curiosidade no } \\
\text { aluno, estimulando } \\
\text { a construção do } \\
\text { conhecimento. }\end{array}$ & $\begin{array}{l}\text { - Demonstrar confiança na } \\
\text { aprendizagem do seu aluno. } \\
\text { - Encorajar os seus alunos a } \\
\text { estudarem, mostrando os } \\
\text { aspectos positivos da educação. } \\
\text { - Usar uma comunicação afetiva } \\
\text { e respeitosa com os alunos. } \\
\text { - Oferecer Feedback positivo. } \\
\text { - Criar oportunidades de } \\
\text { interação aluno-professor e } \\
\text { aluno-aluno. }\end{array}$ & $\begin{array}{l}\text { - Jogos } \\
\text { - Construções de blogs } \\
\text { - Uso de filmes/vídeos com } \\
\text { ou sem debates e } \\
\text { discussões }\end{array}$ & $\begin{array}{l}\text { - Base de dados } \\
\text { - Hot potates }\end{array}$ \\
\hline
\end{tabular}

Fonte: Dados de pesquisa (2018)

Esse Quadro 2 mostra que as ferramentas digitais do Moodle são capazes, quando utilizadas com as estratégias pedagógicas adequadas, de permitir que os professores tenham uma relação empática com seus alunos que estão distantes deles fisicamente. Assim, acreditase que o professor empático tornará os processos de ensino e aprendizagem mais tranquilos e prazerosos para o aluno, que se sentirá motivado a aprender na modalidade a distância, fazendo com este não abandone o curso.

2a etapa: Identificação dos respondentes.

Embora, nesta pesquisa a maioria dos respondentes (63\%) sejam do gênero masculino, o número de mulheres não deixa de ser significativo (37\%) e, como observado pela Confederação Nacional da Indústria (CNI), existe uma tendência de crescimento no interesse feminino por ocupações industriais, como por exemplo, nas áreas de Tecnologia da Informação e Eletrônica, que são as áreas de dois dos cursos, foco desta pesquisa. Sobre a faixa etária dos participantes desta pesquisa, tem-se a maioria dos respondentes (44\%) pertencentes a faixa etária entre 16 a 25 anos, sendo estes os alunos que fazem o curso técnico em concomitância com o ensino médio. 
Em seguida, com $29 \%$ dos respondentes, estão os alunos que pertencem à faixa etária de 26 a 35 anos de idade, representando os alunos egressos do ensino médio e, que de acordo com eles, a procura por cursos técnicos é uma opção frente aos cursos superiores. Já $21 \%$ pertencem à faixa de 36 a 50 anos e, 6\% entre 51 a 61 anos de idade, tratando-se dos alunos que estão à procura de uma atualização profissional e/ou uma recolocação no mercado de trabalho.

Na sequência, foi possível verificar o motivo da escolha de se fazer um curso técnico. Sobre esse ponto, constatou-se que todos os respondentes desta pesquisa acreditam que fazer um curso técnico representa ter esperança de conseguirem uma carreira mais rapidamente e, assim, um caminho para a empregabilidade; ou seja, para os alunos o curso técnico irá proporcionar mais chances no mercado de trabalho.

Outro aspecto averiguado na pesquisa foram as cidades onde os respondentes residem. O resultado mostrou que eles estão distribuídos em 50 cidades mineiras, o que mostra o alcance da EaD. Dentre essas cidades, destaca-se o número de alunos que residem em Belo Horizonte (69). As próximas três cidades que aparecem fazem parte da Grande BH: Contagem com 19 alunos, Betim com 13 e Nova Lima com nove alunos. As demais cidades estão distribuídas em todo o Estado de Minas Gerais: Timóteo (seis alunos); Ibirité e Varginha (cinco alunos em cada uma); Leopoldina e Nepomuceno (quatro alunos em cada); Cataguases, Coronel Fabriciano, Curvelo, Divinópolis, Ipatinga e Santa Luzia (três alunos em cada); Santa Bárbara (dois alunos), Aguanil, Além Paraíba, Conselheiro Lafaiete, Elói Mendes, IAPU, Igarapé, Itaúna, João Monlevade, Lagoa Santa, Ouro Branco, Presidente Juscelino, Recreio, Ribeirão das Neves, São José do Jacuri, Sete Lagoas e Três corações (um aluno em cada). Vale ressaltar que cinco alunos não declararam a cidade onde moravam.

3a etapa: Verificação da aplicação dos critérios da neurociência no processo de ensino e aprendizagem.

Para fazer essa verificação, os alunos receberam oito perguntas de múltipla escolha. Para cada pergunta eles poderiam responder se estavam de acordo, se não concordavam ou se concordavam em parte. As respostas estão tabuladas no Quadro 3. 
Quadro 3 - Verificação da aplicação dos critérios da neurociência no processo de ensino e aprendizagem.

\begin{tabular}{|c|c|c|c|c|c|c|}
\hline \multirow{3}{*}{$\begin{array}{l}\text { Questões referentes aos critérios da } \\
\text { Neurociência }\end{array}$} & \multicolumn{6}{|c|}{ Respostas dos alunos } \\
\hline & \multicolumn{2}{|l|}{ SIM } & \multicolumn{2}{|c|}{ NÃO } & \multicolumn{2}{|c|}{ EM PARTE } \\
\hline & Ocorrência & $\%$ & Ocorrência & $\%$ & Ocorrência & $\%$ \\
\hline $\begin{array}{l}\text { 1a Houve flexibilidade de horários de } \\
\text { aula diferenciados? }\end{array}$ & 100 & 57,2 & 26 & 14,8 & 49 & 28 \\
\hline $\begin{array}{lrr}2 \text { a Seus professores } & \text { usaram } \\
\text { diferentes ferramentas } & \text { digitais } \\
\text { presentes no AVA? } & \end{array}$ & 86 & 49,2 & 27 & 15,4 & 62 & 35,4 \\
\hline $\begin{array}{lrr}\text { 3a Houve } & \text { momentos de } \\
\text { aprendizagem } & \text { personalizada, }\end{array}$ & & & & & & \\
\hline $\begin{array}{llrr}\text { considerando } & \text { que alguns alunos } \\
\text { precisavam de } & \text { uma } \\
\text { diferenciada? } & & & \\
\end{array}$ & 68 & 38,9 & 65 & 37,1 & 42 & 24 \\
\hline $\begin{array}{l}\text { 4a Os materiais didáticos foram } \\
\text { variados? }\end{array}$ & 86 & 49,2 & 32 & 18,2 & 57 & 32,6 \\
\hline $\begin{array}{l}5 \text { a As estratégias pedagógicas foram } \\
\text { variadas? }\end{array}$ & 76 & 43,4 & 40 & 22,9 & 59 & 33,7 \\
\hline $\begin{array}{l}\text { 6a Houve atividades que promoveram } \\
\text { a interação entre os alunos e os } \\
\text { professores; alunos e os tutores e; } \\
\text { alunos e alunos? }\end{array}$ & 86 & 49,2 & 26 & 14,8 & 63 & 36 \\
\hline $\begin{array}{l}\text { 7ạ Você foi motivado pela equipe } \\
\text { pedagógica, ou por seu professor } \\
\text { durante o curso? }\end{array}$ & 90 & 51,4 & 39 & 22,3 & 46 & 26,3 \\
\hline $\begin{array}{l}\text { 8a Houve situações nas quais foi } \\
\text { provocada a sua curiosidade em } \\
\text { relação à construção do seu } \\
\text { conhecimento? }\end{array}$ & 123 & 70,3 & 28 & 16 & 24 & 13,7 \\
\hline
\end{tabular}

Fonte: Dados de pesquisa (2018).

Diante dos dados apresentados no Quadro 3, pode-se constatar:

- 1a questão: a maioria $(57,2 \%)$ dos respondentes concorda que existe flexibilidade de horários de aula diferenciada, o que indica uma preocupação em oferecer aos alunos a possibilidade de cada um usar seus melhores horários para realizar seus estudos.

- 2a questão: a maioria $(49,2 \%)$ dos respondentes concorda que os professores usam as diferentes ferramentas digitais presentes no AVA (apresentadas no Quadro 1). Dentre 
os alunos que não concordam, a justificativa foi: os professores deveriam usar mais ferramentas acadêmicas para o curso ficar mais atraente. Portanto, infere-se que os professores ainda não estejam explorando todas as ferramentas digitais que o Moodle oferece.

- 3a questão: a maior parte $(38,9 \%)$ dos respondentes concorda que houve momentos de aprendizagem personalizada. Porém, chama a atenção nesse ponto, o fato de que a porcentagem de alunos que não concordam $(37,1 \%)$ está muito próxima dos que concordam. Para esses alunos que discordaram: faltou atenção dos professores para com os alunos e eles sentiram os professores e tutores ausentes.

- 4a questão: a maior parte $(49,2 \%)$ dos respondentes concorda que os materiais didáticos foram variados. Dos $18,2 \%$ que discordam e dos $32,6 \%$ que concordam em parte, os materiais estão desatualizados o que para eles é um descaso. Os alunos também informaram que os professores e tutores a distância apenas têm utilizado questionários e tarefas.

- 5a questão: a maioria $(43,4 \%)$ dos respondentes concorda que as estratégias pedagógicas são variadas. Porém, dentre os $22,9 \%$ dos respondentes que discordam a justificativa foi: a didática dos professores deixa a desejar.

- 6a questão: a maior parte dos respondentes $(49,2 \%)$ concorda que houve atividades que promoveram a interação entre os alunos e os professores; alunos e os tutores e; alunos e alunos. De acordo com os alunos, essas atividades são realizadas nos Fóruns e Chats.

- $\quad$ 7ạ questão: a maioria dos respondentes $(51,4 \%)$ concorda que foi motivada pela equipe pedagógica ou por seu professor durante o curso. Essa questão é fundamental para a permanência dos alunos no curso, pois como afirma Gagné (1985), a motivação é uma pré-condição para a aprendizagem. Já para os $26,3 \%$ alunos que concordaram em parte, a justificativa foi: o curso é bom, eles se sentem motivados, mas ainda está desorganizado.

- $\quad$ 8 questão: a maioria dos respondentes $(70,3 \%)$ concorda que houve situações nas 
quais foi provocada a sua curiosidade em relação à construção do seu conhecimento, devido principalmente, segundo os alunos, os encontros presenciais nos pólos. Além disso, para eles a EaD é uma nova forma de aprendizado, que oferece infinitas possibilidades de adquirir o conhecimento e provocar a suas curiosidades. Isso ratifica a análise de Martins et al. (2017) que destacam a importância das emoções, de descobrir o novo para aprender.

Portanto, cabe observar que todos os critérios da neurociência têm sido aplicados nos cursos técnicos a distância do CEFET-MG, alguns ainda de forma tímida ( 3 ㅇ e 5o critérios) e outros com maior ênfase, como por exemplo, os 1ำ e 8o critérios. Tal observação converge para as ideias de Grossi e Borja (2016) que acreditam ser possível aplicar os critérios da neurociência em cursos a distância, devido às tecnologias presentes nos Moodle do CEFETMG (Quadro 1), que permitem a interação entre professores e alunos que estejam distantes fisicamente, que conforme apontado por Prado (s.d.) são ferramentas de fácil manipulação e podem proporcionar uma riqueza de implicações pedagógicas.

4a etapa: Verificação das atitudes dos professores em relação à empatia.

Para fazer essa verificação, os alunos receberam oito perguntas de múltipla escolha. Para cada pergunta, assim como na $2^{\underline{a}}$ parte, eles poderiam responder se concordavam, se não concordavam ou se concordavam em parte. As respostas estão tabuladas no Quadro 4. 
Quadro 4 - Verificação das atitudes dos professores em relação à empatia

\begin{tabular}{|c|c|c|c|c|c|c|}
\hline \multirow{3}{*}{$\begin{array}{l}\text { Questões referente às atitudes dos } \\
\text { professores }\end{array}$} & \multicolumn{6}{|c|}{ Respostas dos alunos } \\
\hline & \multicolumn{2}{|l|}{ Sim } & \multicolumn{2}{|c|}{ Não } & \multicolumn{2}{|c|}{ Em parte } \\
\hline & Ocorrência & $\%$ & Ocorrência & $\%$ & Ocorrência & $\%$ \\
\hline 1a Os professores procuraram & & & & & & \\
\hline $\begin{array}{l}\text { conhecer sua realidade e } \\
\text { necessidade? }\end{array}$ & 45 & 25,7 & 78 & 44,6 & 52 & 29,7 \\
\hline 2a Seus professores tiveram & & & & & & \\
\hline $\begin{array}{l}\text { flexibilidade em relação às datas das } \\
\text { atividades? }\end{array}$ & 104 & 59,4 & 30 & 17,1 & 41 & 23,5 \\
\hline $\begin{array}{l}\text { 3a Os professores demonstraram } \\
\text { confiança na sua aprendizagem? }\end{array}$ & 94 & 53,7 & 31 & 17,7 & 50 & 28,6 \\
\hline 4a Os professores demonstraram & & & & & & \\
\hline $\begin{array}{l}\text { preocupação } \\
\text { aprendizagem? }\end{array}$ & 77 & 44 & 40 & 22,9 & 58 & 33,1 \\
\hline $\begin{array}{l}\text { 5a Os professores te encorajaram a } \\
\text { estudar, mostrando os aspectos } \\
\text { positivos da educação? }\end{array}$ & 77 & 44 & 44 & 25,1 & 54 & 30,9 \\
\hline 6a Ofereceram feedback positivo? & 68 & 38,9 & 45 & 25,7 & 62 & 35,4 \\
\hline 7ạ Criaram oportunidades de & & & & & & \\
\hline $\begin{array}{l}\text { interação aluno-professor e aluno- } \\
\text { aluno? }\end{array}$ & 75 & 42,8 & 36 & 20,6 & 64 & 36,6 \\
\hline 8a No caso de situações & & & & & & \\
\hline $\begin{array}{l}\text { problemáticas, os professores } \\
\text { procuraram soluções? }\end{array}$ & 99 & 56,6 & 20 & 11,4 & 56 & 32 \\
\hline
\end{tabular}

Fonte: Dados de pesquisa (2018)

Tendo em vista os dados apresentados no Quadro 4, entende-se que:

- 1a questão: a maior parte dos respondentes $(44,6 \%)$ discorda que os professores procuraram conhecer suas realidades e necessidades, ressaltando que tiveram contato na maior parte do tempo apenas com o tutor, e que o corpo docente demonstrou, por vezes, uma atitude desinteressada. Isso indica uma necessidade em esclarecer os papéis de professores e tutores na interação com os alunos.

- 2a questão: a maioria $(59,4 \%)$ dos respondentes concorda que os professores tiveram flexibilidade em relação às datas das atividades. Para os $23,5 \%$ que responderam em parte, nem todos os professores estavam à disposição para responder as perguntas, $e$ quando tinha retorno era demorado. Também apontaram problemas de organização do curso, dificuldades de comunicação e perguntas sem respostas no fórum. 
- 3a questão: a maioria $(53,7 \%)$ dos respondentes concorda que os professores demonstraram confiança em sua aprendizagem. Os $28,6 \%$ que responderam em parte, justificaram que não poderia se afirmar que todos os professores respondem bem às nossas necessidades, principalmente porque o contato pessoal foi praticamente com o professor mediador.

- 4a questão: a maior parte dos respondentes (44\%) concordou que os professores demonstraram preocupação com a aprendizagem dos alunos. Porém, dentre os $33,1 \%$ que discordam, o entendimento é que há descaso dos professores em relação às dificuldades de cada um.

- 5a questão: a maior parte dos respondentes (44\%) concordou que os professores encorajaram os alunos a estudar, mostrando aspectos positivos da educação. Para exemplificar, alguns alunos comentaram que os professores sempre respondiam aos emails, para tirar qualquer dúvida, orientação, ajuda. Ressaltaram que os tutores também, sempre estiveram presentes e nos incentivavam a estudar, tirar dúvidas, enviavam links para aprendermos mais da disciplina de cada professor.

- 6a questão: a maior parte dos respondentes $(38,9 \%)$ concorda que os professores ofereceram feedback positivo. Porém, um número muito próximo de respondentes $(35,4 \%)$, afirmaram que isso ocorreu apenas em parte. Eles relataram que tiveram problemas com retornos dos professores sobre dúvidas e até mesmo sobre recuperações, que ainda não haviam sido sanadas, até a data que responderam o questionário.

- 7ạ questão: a maior parte dos respondentes $(42,8 \%)$ concorda que foram criadas oportunidades de interação aluno-professor e aluno-aluno. No entanto, alguns alunos informaram que sentiram falta de conhecerem os demais professores do curso, além de um tutor que tiveram maior contato nas aulas presenciais.

- $\quad$ a questão: a maioria dos respondentes $(56,6 \%)$ concorda que no caso de situações problemáticas, os professores procuraram soluções. Não houve comentários específicos sobre esse critério. 
Assim, a partir das respostas e comentários dos alunos, pode-se afirmar que a empatia é um importante aspecto nas relações interpessoais e merece atenção na $\mathrm{EaD}$, visto que as interações mediadas pelas ferramentas digitais nos AVA pressupõem uma distância física e temporal que podem acarretar outro tipo de distância de ordem comunicacional e psicológica. Entende-se que o exercício da empatia seja capaz de minimizar essa distância.

Em muitos comentários, os alunos demonstraram a importância da comunicação com professores e tutores, e como esta pode influenciar na permanência dos alunos em um curso a distância apesar das dificuldades encontradas. Isso reforça a afirmação de Moore e Kearsley (2013, p. 179) de que "o melhor professor a distância tem empatia e capacidade para entender as personalidades de seus alunos, mesmo quando filtradas pelas comunicações transmitidas tecnologicamente". Dessa forma, conclui-se que várias dentre as sete atitudes que os professores devem ter para estabelecerem uma relação de empatia com seus alunos estiveram presentes nas respostas dos alunos, destacando: Flexibilidade; Demonstração de confiança no processo de aprendizagem dos alunos; e Encorajar e motivar os alunos a estudarem, mostrando os aspectos positivos da educação.

5a etapa: Sobre a permanência.

Para verificar por que os alunos não desistiram do curso, foram feitas a eles duas perguntas de múltipla escolha, nas quais deveriam responder sim ou não (Quadro 5).

Quadro 5 - Sobre a permanência.

\begin{tabular}{|c|c|c|c|c|}
\hline \multirow{3}{*}{ Questões referentes à permanência } & \multicolumn{4}{|c|}{ Respostas dos alunos } \\
\hline & Sim & & Não & \\
\hline & Ocorrência & $\%$ & Ocorrência & $\%$ \\
\hline 1a Você pensou em desistir do curso? & 61 & 34,9 & 114 & 65,1 \\
\hline $\begin{array}{l}\text { 2a Você considera que a forma como acontece a relação } \\
\text { entre os alunos e os professores pode ajudar o aluno a não } \\
\text { desistir do curso? }\end{array}$ & 141 & 80,6 & 34 & 19,4 \\
\hline
\end{tabular}

Fonte: Dados de pesquisa (2018).

Tendo em vista os dados apresentados no Quadro 5 e os comentários dos respondentes, percebeu-se que:

- 1a questão: a maioria dos respondentes $(65,1 \%)$ respondeu que não pensaram em desistir do curso. Dentre os demais (34,9\%), os principais motivos expressos pelos 
alunos para uma possível evasão abarcam questões de ordem pessoal, como dificuldades com o conteúdo, organização pessoal e dificuldades no deslocamento para as aulas presenciais; problemas de qualidade e organização do curso, como atrasos no calendário; e problemas referentes à comunicação.

- 2a questão: a maioria dos respondentes $(80,6 \%)$ considera que a forma como acontece a relação entre alunos e professores pode ajudar o aluno a não evadir. Comentários apontaram que os principais pontos de atenção estão na comunicação entre professores e alunos para resolução de dúvidas e feedbacks, que precisam ser melhorados.

Percebe-se, portanto, que muitos são os motivos para o abandono do curso pelos alunos, na modalidade a distância. Problemas pessoais como dificuldades com a organização pessoal e com o aprendizado são destacados por eles, mas apesar destes fatores, a maioria dos respondentes informou que não pensou em desistir do curso. Além das motivações pessoais para almejar a conclusão, pode-se inferir o que defende Migliori (2013, p. 77) quando afirma que "a vontade de aprender é característica essencial do ser humano, mas necessita de estímulos externos e internos, motivação e necessidades". Nos comentários, identificouse a importância que os alunos deram às interações realizadas com os professores e, principalmente tutores, no esclarecimento de dúvidas, apoio ao aprendizado e incentivo a continuar com o curso, sendo fundamentais para a permanência no curso.

\section{Considerações finais}

A aplicação dos conhecimentos da neurociência na educação é fundamental para os professores saberem como seus alunos aprendem e, assim possam dentre uma variedade de estratégias pedagógicas, saber escolher as que conseguem atingi-los e promover a aprendizagem, estimulando externamente seus alunos e contribuindo para que estes consigam acionar o gatilho do estímulo interno. Portanto, a introdução da neurociência precisa ser considerada em todas as modalidades de ensino, como por exemplo, na EaD, que foi o foco desse estudo.

Nesta pesquisa foram apresentados os oito critérios da neurociência aplicados no 
processo de ensino e aprendizagem, procurando identificar se eles eram atendidos a partir do uso das ferramentas digitais do Moodle, presentes nas diversas estratégias pedagógicas dos cursos ofertados a distância do CEFET-MG. Os achados da pesquisa permitem concluir que todos os oito critérios foram atendidos, sobressaindo a flexibilidade de horários de aula diferenciados (1으 critério); provocação da curiosidade do aluno em relação à construção do seu conhecimento (8o critério); a motivação do aluno pela equipe pedagógica, ou pelo professor durante o curso (70 critério); o uso de atividades que promoveram a interação entre alunos-professores; alunos-tutores e alunos-alunos (60 critério). 0 critério que teve menor destaque foi o 3 o critério, o qual está relacionado com a existência de momentos de aprendizagem personalizada.

Portanto, pode-se afirmar que as tecnologias existentes garantem o desenvolvimento de AVA que ampliam as possibilidades de interação e comunicação entre alunos e professores, mesmo quando estes não estão juntos fisicamente. Adicionalmente, verificou-se para cada critério da neurociência (conjugado com diferentes estratégias pedagógicas específicas e com o uso das ferramentas digitais do Moodle), se houve empatia entre professor e aluno da EaD. Como resultado, pode-se observar que, embora a maioria dos alunos $(44,6 \%)$, os professores não demonstraram interesse sobre suas realidades e necessidades individuais, em todos as demais sete atitudes empáticas (Quadro 4), os professores apresentaram uma atitude empática positiva, tais como: demonstraram confiança na aprendizagem dos alunos; demonstraram preocupação com suas aprendizagens; os encorajaram a estudar; criaram oportunidades de interação aluno-professor e aluno-aluno; deram feedbacks positivos e, flexibilizaram as datas das atividades.

Assim, a questão que originou esta pesquisa: Como estabelecer a relação empática entre quem está distante fisicamente e/ou temporalmente? tem como resposta o que os professores da Turma de 2018 começaram a fazer para evitar a evasão: levar para suas salas de aula virtuais estratégias pedagógicas que estão motivando seus alunos, mantendo com estes uma relação de proximidade e afetividade e, estabelecendo a empatia. A presente pesquisa evidenciou que os alunos demonstraram querer estabelecer uma comunicação dialógica com seus professores, bem como ser compreendidos por eles. 
Por fim, conclui-se que, nos cursos técnicos a distância do CEFET-MG - Turma 2018, os professores têm usado os critérios da neurociência, praticando a comunicação dialógica afetiva e, estabelecendo uma relação empática com seus alunos. E é essa relação empática que está encantando os alunos, mantendo-os mais motivados a continuar no curso, apesar das dificuldades que os alunos vêm encontrando durante o mesmo. Então, espera-se que os números de evasão dessa turma sejam menores do que os apresentados nos anos anteriores.

\section{Referências}

ASSOCIAÇÃO BRASILEIRA DE EDUCAÇÃO A DISTÂNCIA - ABED. Censo EAD.BR: relatório analítico da aprendizagem a distância no Brasil /2016. Disponível em:

http://abed.org.br/censoead2016/Censo_EAD_2016_portugues.pdf. Acesso em: 13 jul. 2018.

BRASIL. CONSELHO NACIONAL DE EDUCAÇÃO CÂMARA DE EDUCAÇÃO BÁSICA. Resolução CNE/CEB no 6 de 20 de setembro de 2012. Define Diretrizes Curriculares Nacionais para a Educação Profissional Técnica de Nível Médio. Brasília, 2012. Disponível em: http://portal.mec.gov.br/index.php?option=com_docman\&view=download\&alias=11663rceb006-12-pdf\&category_slug=setembro-2012-pdf\&Itemid=30192. Acesso em: 21 maio 2018.

BRASIL. Lei no 13.415 de 16 de fevereiro de 2017. Dispõe sobre a alteração da Lei $n^{0} 9.394$, de 20 de dezembro de 1996 e estabelece as diretrizes e bases da educação nacional. Disponível em: http://www.planalto.gov.br/ccivil_03/_ato2015-2018/2017/lei/l13415.htm. Acesso em: 06 jul. 2018.

BRASIL. Lei no 9.394 de 20 de dezembro de 1996. Estabelece as diretrizes e bases da educação nacional. Disponível em: http://www.planalto.gov.br/ccivil_03/_ato20152018/2017/lei/l13415.htm. Acesso em: 06 jul. 2018.

BRASIL. MINISTÉRIO DA EDUCAÇÃO Decreto no 7.589 de 26 de outubro de 2011. Institui a Rede e-Tec Brasil. Disponível em:

http://redeetec.mec.gov.br/index.php?option=com_content\&view=article\&id=11\&lte mid=1. Acesso em: 14 jul. 2018.

BRASIL. MINISTÉRIO DA EDUCAÇÃO. Associação Brasileira de Mantenedoras do Ensino Superior. Portaria no 1.134, de 10 de outubro de 2016. Dispõe sobre a revogação da Portaria MEC no 4.059, de 10 de dezembro de 2004, e estabelece nova redação para o tema. Disponível em: https://abmes.org.br/legislacoes/detalhe/1988/portaria-n-1134. Acesso em: 06 jul. 2018.

BRASIL. MINISTÉRIO DA EDUCAÇÃO. Decreto no. 6.301 de 12 de dezembro de 2007. Institui o Sistema Escola Técnica Aberta do Brasil, e-Tec Brasil. Disponível em: https://www.planalto.gov.br/ccivil_03/_ato2007-2010/2007/decreto/d6301.htm. Acesso 
em: 06 nov. 2019.

BZUNECK, J. A. A motivação do aluno: aspectos introdutórios. In: BORUCHOVITCH, E.; BZUNECK, J. A. (org.). A motivação do aluno: contribuições da psicologia contemporânea. Petrópolis: Vozes, 2009, p. 9 - 36.

CARMO, C. A. A teoria da distância transacional: para um modelo pedagógico na formação continuada de professores a distância. 2016. Disponível em: http://www.siedenped2016.ead.ufscar.br/ojs/index.php/2016/article/view/1030/793. Acesso em: 06 jul. 2018.

CARTER, R.; ALDRIGE, S.; PAGE, M.; PARKER, S. O livro do Cérebro. Rio de Janeiro: Agir, 2012. CONFEDERAÇÃO NACIONAL DA INDUSTRIAL - CNI. Cresce interesse feminino por ocupações industriais, 2018. Disponível em:

https://noticias. portaldaindustria.com.br/noticias/educacao/cresce-interesse-feminino-porocupacoes-industriais/. Acesso em: 01 set. 2018.

COSENZA, R. M.; GUERRA, L. B. Neurociência e educação: como o cérebro aprende. Porto Alegre: Artmed, 2014.

FARIA, E. V. O tutor na Educação a Distância: A construção de conhecimentos pela interação nos ambientes midiáticos no contexto da educação libertadora. Scientia FAER, Olímpia, São Paulo, ano 2, v. 2, p. 28-37, 2010.

GAGNÉ, R. M. Las condiciones dei aprendizaje. México: Trillas, 1985.

GROSSI, M. G. R. G.; CHAMON, C. M.; ELIAS, M. C. S.; LEAL, D. C. C. C. The Educational Potentialities of the Virtual Learning Environments Moodle and Canvas: A Comparative Study. International Journal of Information and Education Technology, v. 8, n. 7, p. 514519, 2018.

GROSSI, M. G. R.; BORJA, S. D. B. A neurociência e a educação a distância: um diálogo necessário. Revista Tempos e Espaços em Educação, v. 9, n. 19, p. 87-102, mai./ago. 2016.

GROSSI, M. G. R.; BORJA, S. D. B. O ensino de língua estrangeira a distância: a percepção de alunos do curso Livemocha. Paidéi@, Santos, v. 7, p. 1-21, 2015.

GROSSI, M. G. R; LOPES, A. M.; COUTO. P. A. A neurociência na formação de professores: um estudo da realidade brasileira. Revista da FAEEBA de Educação e Contemporaneidade, Salvador, v. 23, n. 41, p. 27 - 40, jan./jun. 2014.

HACK, J. R. Afetividade em processos comunicacionais de tutoria no ensino superior a distância. Florianópolis: Virtual Educa, 2010. Disponível em:

http://www.hack.cce.prof.ufsc.br/wpntent/uploads/2010/01/VirtualEduca_2010_Hack.pdf. Acesso em: 07 jul. 2018.

INSTITUTO BRASILEIRO DE GEOGRAFIA E ESTATÍSTICA - IBGE Pesquisa nacional por amostra de domicílios - PNAD Contínua. 2016. Disponível em:

http://ftp.ibge.gov.br/Trabalho_e_Rendimento/Pesquisa_Nacional_por_Amostra_de_Domic 
ilios_continua/Anual/Acesso_Internet_Televisao_e_Posse_Telefone_Movel_2016/Analise_d os_Resultados.pdf. Acesso em: 06 jul. 2018.

KANDEL, E. R.; SCHWARTZ, J. H.; JESSEL, T. M.; SIEGELBAUM, S. A.; HUDESPETH, A. J. Princípios de neurociências. Porto Alegre: AMGH, 2014.

LOURENÇO, A. A.; DE PAIVA, M. O. A motivação escolar e o processo de aprendizagem. Ciências \& Cognição, v. 15, n. 2, p. 132-141, 2010.

MARTINS, I. M.; PEDROSA, M. M.; MATOSO, M. Cá dentro: Guia para descobrir o cérebro. Lisboa: Planeta Tangerina, 2017.

MIGLIORI, R. Neurociências e educação. São Paulo: Brasil Sustentável Editora, 2013.

MOODLE. Atividades Moodle. Disponível em: https://docs.moodle.org/35/en/Activities. Acesso em: 28 jul. 2018.

MOORE, M. G. Teoria da distância transacional. In: KEEGAN, D. Theoretical Principles of distance education. Londres: Routledge, 1993. p. 22-38.

MOORE, M. G.; KEARSLEY; G. Educação a distância: sistemas de aprendizagem online. São Paulo: Cengage Learning, 2013.

NOVAES, M. H. Repensando a formação e o exercício profissional do psicólogo escolar na sociedade pós-moderna. In: ALMEIDA, S. F. C. (org.). Psicologia Escolar: éticas e competências na formação e atuação profissional. São Paulo: Alínea, 2010, p. 127-134.

OLIVEIRA, P. H. O ambiente Virtual de aprendizagem e evasão escolar: Estudo de caso em uma instituição pública de Minas Gerais. 2017. 90 f. Dissertação (Mestrado em Educação Tecnológica) - Programa de Pós-Graduação em Educação Tecnológica, Centro Federal de Educação Tecnológica de Minas Gerais, Belo Horizonte, 2017.

PRADO, M. E. B. B. Educação a distância: os ambientes virtuais e algumas possibilidades pedagógicas. Projeto Gestão Escolar e Tecnologias. Pontifícia Universidade Católica de São Paulo. Disponível em: http://www.eadconsultoria.com.br/matapoio/biblioteca. Acesso em: 08 jul. 2018.

RIBEIRO, F. Motivação e aprendizagem em contexto escolar. Profforma, n. 3, p. 1-5, 2011.

TASSINARI, M. A.; DURANGE, W. T. Experiência empática: Da neurociência à espiritualidade. Revista da Abordagem Gestáltica e Phenomenological Studies, v. xx, n. 1, p. 53-60, 2014.

VALENTE, J. A.; MORAN, J. M.; ARANTES, V. A. (org.). Educação a distância: pontos e contrapontos. São Paulo: Summus, 2011.

VIGNEMONT, F.; SINGER, T. The empathic brain: how, when and why? Trends in Cognitive Sciences, Elsevier. 2006. Disponível em: https://jeannicod.ccsd.cnrs.fr/ijn_00169584/document. Acesso em: 07 jul. 2018.

Recebido em: 29/12/2018 Aprovado em: 02/08/2019 